\title{
Cardiac amyloidosis: A new challenge of multimodality imaging
}

\author{
Carmela Nappi, MD, ${ }^{\mathrm{a}}$ Roberta Assante, $\mathrm{MD}, \mathrm{PhD},{ }^{\mathrm{a}}$ Emilia Zampella, $\mathrm{MD}, \mathrm{PhD},{ }^{\mathrm{a}}$ \\ and Alberto Cuocolo, MD \\ a Department of Advanced Biomedical Sciences, University Federico II, Naples, Italy
}

Received Jun 15, 2018; accepted Jun 15, 2018

doi: $10.1007 / \mathrm{s} 12350-018-1353-1$

\section{See related article, pp. 96-105}

Amyloidosis is a group of multiorgan diseases in which misfolded proteins accumulate as insoluble fibrils (amyloid) in the extracellular space, disrupting the architecture and function of involved organs. ${ }^{1}$ Cardiac amyloidosis is characterized by accumulation of amyloid in the interstice of the cardiac tissue, leading to restrictive cardiomyopathy. Increased ventricular wall thickness and stiffness, with atrial infiltration represent typical signs of disease. ${ }^{2}$ Also, protein deposition in small arterioles of the heart may result in angina symptoms and microvascular dysfunction with reduction of coronary flow reserve. ${ }^{3}$ Given the high mortality rate of the disease, an early diagnosis and a timely therapeutic intervention is necessary. The two most common types of cardiac amyloidosis are the light chain amyloidosis and transthyretin (TTR) amyloidosis. ${ }^{4}$

A number of non-invasive imaging tests are available for diagnosis of disease, exploring different characteristics of the pathology although definitive diagnosis of cardiac amyloidosis is obtained by endomyocardial biopsy. However, this approach is an expensive, invasive method with high risk of compliances requiring high level of technical expertise. ${ }^{5}$ Among non-invasive techniques, the most used are echocardiography with global longitudinal strain (LS) evaluation and cardiac magnetic resonance (MR), in addition to electrocardiographic evaluation. ${ }^{6}$ In detail, pathological echocardiography shows thickened left

Reprint requests: Alberto Cuocolo, MD, Department of Advanced Biomedical Sciences, University Federico II, Naples, Italy; cuocolo@unina.it

J Nucl Cardiol 2020;27:106-8.

$1071-3581 / \$ 34.00$

Copyright (C) 2018 American Society of Nuclear Cardiology. ventricular (LV) wall, retractile myocardium with diastolic dysfunction and reduced global LS with systolic dysfunction. $^{7}$ Nevertheless, only a small number of patients show this modification at early stage of disease. Therefore, this method is not accurate due to low sensitivity and specificity. ${ }^{8}$ On the other hand, cardiac MR imaging can be useful to identify global and subendocardial late gadolinium enhancement, suggestive of presence of amyloidosis, with a high sensitivity but still low specificity. ${ }^{9}$ In addition, the pattern of late gadolinium enhancement may be atypical and patchy. It should be considered that sequencing implementation with introduction of $\mathrm{T} 1$ mapping, allowed a more accurate evaluation of myocardial interstice. It has been shown that non-contrast T1 mapping has high diagnostic accuracy for the detection of cardiac amyloidosis and correlates well with markers of systolic and diastolic dysfunction with high sensitivity for identifying early cardiac disease. ${ }^{10}$ Though, none of these imaging techniques are able to distinguish the two subtypes of cardiac amyloidosis. Recently, the introduction of bone scintigraphy tracers made easier the early diagnosis of TTR amyloidosis, ${ }^{11}$ differentiating between the two common types of amyloidosis. ${ }^{12,13}$ This aspect may have an important rule to subsequent therapeutic strategy and prognostic implications. Indeed, TTR type amyloidosis exhibits similar echocardiographic characteristics of light chain amyloidosis type, although as compared to the latter shows fewer symptoms with better survival. ${ }^{14}$ Bone scintigraphy with radiolabeled diphosphonate represents an accurate and reproducible economical non-invasive method. It has been demonstrated that cardiac uptake on bone scintigraphy allows early diagnosis of the disease, even before abnormalities can be found with echocardiography. ${ }^{15}$ Recent studies also demonstrated the presence of high correlation between cardiac uptake on bone scintigraphy and findings on echocardiography and laboratory parameters. In particular, a significant correlation was found between 
cardiac uptake and LV mass index, which may be a better criterion for cardiac involvement in amyloidosis than LV mean wall thickness. ${ }^{16}$ In addition, there is a significant association between the degrees of cardiac amyloid deposition, as assessed by ${ }^{99 \mathrm{~m}}$ Tc-diphosphonate scans, and strain echocardiography data. ${ }^{17}$ With increased amyloid deposition, a worsening of longitudinal function has been observed.

In the current issue of the Journal, Pradel and coworkers $^{18}$ evaluated the relationship between cardiac uptake by ${ }^{99 \mathrm{~m}}$ Tc-hydroxymethylene-diphosphonate ( ${ }^{99 \mathrm{~m}}$ Tc-HMDP) scintigraphy and LV function. The authors conducted a retrospective study of 50 patients considering as positive for TTR amyloidosis for the presence of a combined visual score of 2 or 3 of myocardial ${ }^{99 m}$ Tc-HMDP uptake on bone scintigraphy and the absence of a monoclonal protein in serum or urine. For all patients, at imaging evaluation, semiquantitative analysis of heart/whole body $(\mathrm{H} / \mathrm{WB})$ ratio was performed, beyond a quantitative myocardial uptake obtained using an automated software. All patients also underwent a transthoracic echocardiography and myocardial LS, LV volumes, and ejection fraction were calculated. The authors found a correlation between myocardial ${ }^{99 \mathrm{~m}}$ Tc-HMDP uptake and H/ WB ratio. As already demonstrated above, there was a basal to apical gradient for ${ }^{99 \mathrm{~m}} \mathrm{Tc}-\mathrm{HMDP}$ uptake, which mimics the echocardiographic pattern of basal to apical gradient of LS. However, in the study by Pradel et $\mathrm{al}^{18}$ the correlation between segmental bone tracer uptake and LS was slightly. With regard to myocardial ${ }^{99 \mathrm{~m}}$ Tc-HMDP uptake, no differences between basal and mid segments were observed. In addition, there was no correlation between relative apical bone tracers' uptake and relative apical LS. Furthermore, the authors found a significant correlation between H/WB ratio and global LS, LV wall thickness and diastolic function, without any impact on LV ejection fraction. The results of this study highlight the possibility that the relationship between bone tracers' myocardial uptake and LV morphology and function represent a complex process that involved many factors. Moreover, the study proposed by Pradel et $\mathrm{al}^{18}$ may point out the relevance to evaluate the different regional involvement by looking at each myocardial segment uptake, which may reflect different pathological state of disease. In addition, they focalized on the early appearance of LV wall thickening alteration and diastolic dysfunction, before the systolic dysfunction occurs in the later stages of disease.

Recent studies ${ }^{19,20}$ demonstrated the presence of a base to apex gradient with an apical sparing of ${ }^{99 \mathrm{~m}} \mathrm{Tc}$ HMDP uptake in patients with TTR amyloidosis, suggesting that a correlation can be made between ${ }^{99 \mathrm{~m}} \mathrm{Tc}$ -
HMDP scintigraphy and transthoracic echocardiography or cardiac MR imaging concerning the segmental amyloid burden. In agreement with the study presented in the current issue of the Journal, ${ }^{18}$ both Van Der Gucht et $\mathrm{al}^{19}$ and Sperry et $\mathrm{al}^{20}$ outlined the importance to quantify ${ }^{99 m}$ Tc-HMDP cardiac segmental uptake in TTR amyloidosis, to monitor the progression of disease. This aspect may be useful for future trial to establish the assessment of therapy response. However, the relevant aspect of the study proposed by Pradel et al $^{18}$ was represented by the weak association between segmental bone tracer uptake and LS. This aspect reinforces the concept that cardiac amyloidosis represents a complex process involving different clinical, hemodynamics, and imaging aspects. In this context, a non-invasive evaluation by multimodality approach is necessary for early diagnosis, monitoring progression disease and choose the best treatment strategy. The role of different imaging techniques in establishing the timing of response to treatment in amyloidosis remains to be clarified. Of note, the availability of state-of-the-art hybrid technologies with higher temporal and spatial resolution such as positron emission tomography/computed tomography (PET/CT) or PET/MR associated with novel amyloid-imaging agents, such as ${ }^{18} \mathrm{~F}$-Florbetapir and ${ }^{11} \mathrm{C}$-Pittsburgh B (PIB), may help to identify early imaging biomarkers of disease, for early intervention and targeted treatment. ${ }^{21,22}$ Indeed, hybrid imaging approach has already demonstrated a potential role in detection of cardiac involvement in other storage accumulation multiorgan disease, ${ }^{23,24}$ showing a correlation between impairment of $\mathrm{LV}$ longitudinal function and focal tracer uptake in females carrying $\alpha$-Gal A mutation, as early sign of disease-related myocardial damage. ${ }^{25}$ Therefore, other studies are needed for evaluating a correct multimodality approach to cardiac involvement of amyloidosis, considering the increasingly important and emerging role of the molecular imaging and the relevance of personalized and correctly addressed therapy.

\section{Disclosure}

C. Nappi, R. Assante, E. Zampella, and A. Cuocolo declare that they have no conflict of interest.

\section{References}

1. Banypersad SM, Moon JC, Whelan C, Hawkins PN, Wechalekar AD. Updates in cardiac amyloidosis: A review. J Am Heart Assoc 2012;1:e000364.

2. Siddiqi OK, Ruberg FL. Cardiac amyloidosis: An update on pathophysiology, diagnosis, and treatment. Trends Cardiovasc Med 2018;28:10-21.

3. Dorbala S, Vangala D, Bruyere J Jr, Quarta C, Kruger J, Padera R, et al. Coronary microvascular dysfunction is related to 
abnormalities in myocardial structure and function in cardiac amyloidosis. JACC Heart Fail.- 2014;2:358-67.

4. Rapezzi C, Quarta CC, Riva L, Longhi S, Gallelli I, Lorenzini M, et al. Transthyretin-related amyloidoses and the heart: A clinical overview. Nat Rev Cardiol 2010;7:398-408.

5. Veinot JP. Diagnostic endomyocardial biopsy-still useful after all these years. Can J Cardiol 2009;25:e55-6.

6. Piper C, Butz T, Farr M, Faber L, Oldenburg O, Horstkotte D. How to diagnose cardiac amyloidosis early: Impact of ECG, tissue Doppler echocardiography, and myocardial biopsy. Amyloid 2010;17:1-9.

7. Koyama J, Ray-Sequin PA, Falk RH. Longitudinal myocardial function assessed by tissue velocity, strain, and strain rate tissue Doppler echocardiography in patients with al (primary) cardiac amyloidosis. Circulation 2003;107:2446-52.

8. Maurer MS. Noninvasive identification of ATTRwt cardiac amyloid: The re-emergence of nuclear cardiology. Am J Med 2015;128:1275-80.

9. Maceira AM, Joshi J, Prasad SK, Moon JC, Perugini E, Harding I, et al. Cardiovascular magnetic resonance in cardiac amyloidosis. Circulation 2005;111:186-93.

10. Karamitsos TD, Piechnik SK, Banypersad SM, Fontana M, Ntusi $\mathrm{NB}$, Ferreira VM, et al. Noncontrast T1 mapping for the diagnosis of cardiac amyloidosis. JACC Cardiovasc Imaging 2013;6:488-97.

11. Treglia G, Glaudemans AWJM, Bertagna F, Hazenberg BPC, Erba PA, Giubbini R, et al. Diagnostic accuracy of bone scintigraphy in the assessment of cardiac transthyretin-related amyloidosis: A bivariate meta-analysis. Eur J Nucl Med Mol Imaging 2018. https://doi.org/10.1007/s00259-018-4013-4.

12. Perugini E, Guidalotti PL, Salvi F, Cooke RM, Pettinato C, Riva $\mathrm{L}$, et al. Noninvasive etiologic diagnosis of cardiac amyloidosis using $\quad{ }^{99 \mathrm{~m}} \mathrm{Tc}-3,3$-diphosphono-1,2-propanodicarboxylic acid scintigraphy. J Am Coll Cardiol 2005;46:1076-84.

13. Bokhari S, Castaño A, Pozniakoff T, Deslisle S, Latif F, Maurer MS. ${ }^{99 \mathrm{~m}} \mathrm{Tc}$-pyrophosphate scintigraphy for differentiating lightchain cardiac amyloidosis from the transthyretin-related familial and senile cardiac amyloidoses. Circ Cardiovasc Imaging 2013;6:195-201

14. Ogiwara F, Koyama J, Ikeda S, Kinoshita O, Falk RH. Comparison of the strain Doppler echocardiographic features of familial amyloid polyneuropathy (FAP) and light-chain amyloidosis. Am J Cardiol 2005;95:538-40.

15. Rapezzi C, Quarta CC, Guidalotti PL, Pettinato C, Fanti S, Leone $\mathrm{O}$, et al. Role of ${ }^{99 \mathrm{~m}} \mathrm{Tc}$-DPD scintigraphy in diagnosis and prognosis of hereditary transthyretin-related cardiac amyloidosis. JACC Cardiovasc Imaging 2011;4:659-70.
16. Glaudemans AW, van Rheenen RW, van den Berg MP, Noordzij W, Koole M, Blokzijl H, et al. Bone scintigraphy with ${ }^{99 \mathrm{~m}} \mathrm{Tc}-$ hydroxymethylene diphosphonate allows early diagnosis of cardiac involvement in patients with transthyretin-derived systemic amyloidosis. Amyloid 2014;21:35-44.

17. Di Bella G, Minutoli F, Piaggi P, Casale M, Mazzeo A, Zito C, et al. Quantitative comparison between amyloid deposition detected by ${ }^{99 \mathrm{~m}} \mathrm{Tc}$-diphosphonate imaging and myocardial deformation evaluated by strain echocardiography in transthyretinrelated cardiac amyloidosis. Circ J 2016;80:1998-2003.

18. Pradel S, Brun S, Victor G, Pascal P, Fournier P, Ribes D, et al. Pattern of myocardial ${ }^{99 \mathrm{~m}} \mathrm{Tc}-\mathrm{HMDP}$ uptake and impact on myocardial function in patients with transthyretin cardiac amyloidosis. J Nucl Cardiol 2018. https://doi.org/10.1007/s12350-0181316-6.

19. Van Der Gucht A, Cottereau AS, Abulizi M, Guellich A, BlancDurand P, Israel JM, et al. Apical sparing pattern of left ventricular myocardial ${ }^{99 \mathrm{~m}} \mathrm{Tc}-\mathrm{HMDP}$ uptake in patients with transthyretin cardiac amyloidosis. J Nucl Cardiol 2017. https://doi.org/10.1007/ s12350-017-0894-z.

20. Sperry BW, Vranian MN, Tower-Rader A, Hachamovitch R, Hanna M, Brunken $R$, et al. regional variation in technetium pyrophosphate uptake in transthyretin cardiac amyloidosis and impact on mortality. JACC Cardiovasc Imaging 2018;11:234-42.

21. Dorbala S, Vangala D, Semer J, Strader C, Bruyere JR Jr, Di Carli $\mathrm{MF}$, et al. Imaging cardiac amyloidosis: A pilot study using ${ }^{18} \mathrm{~F}$ florbetapir positron emission tomography. Eur J Nucl Med Mol Imaging 2014;41:1652-62.

22. Minamimoto R, Awaya T, Iwama K, Hotta M, Nakajima K, Hirai R, et al. Significance of (11) C-PIB PET/CT in cardiac amyloidosis compared with (99m) Tc-aprotinin scintigraphy: A pilot study. J Nucl Cardiol 2018. https://doi.org/10.1007/s12350-018-1260-5.

23. Nappi C, Altiero M, Imbriaco M, Nicolai E, Giudice CA, Aiello $M$, et al. First experience of simultaneous PET/MRI for the early detection of cardiac involvement in patients with Anderson-Fabry disease. Eur J Nucl Med Mol Imaging 2015;42:1025-31.

24. Imbriaco M, Pellegrino T, Piscopo V, Petretta M, Ponsiglione A, Nappi C, et al. Cardiac sympathetic neuronal damage precedes myocardial fibrosis in patients with Anderson-Fabry disease. Eur J Nucl Med Mol Imaging 2017;44:2266-73.

25. Spinelli L, Imbriaco M, Nappi C, Nicolai E, Giugliano G, Ponsiglione A, et al. Early cardiac involvement affects left ventricular longitudinal function in females carrying $\alpha$-galactosidase $\mathrm{A}$ mutation: Role of hybrid positron emission tomography and magnetic resonance imaging and speckle-tracking echocardiography. Circ Cardiovasc Imaging 2018;11:e007019. 